\title{
A Educação Matemática via Ambiente Virtual e a Educação Inclusiva: ações de um Laboratório de Ensino de Geometria
}

\author{
Ana Maria M. R. Kaleff \\ Universidade Federal Fluminense \\ anakaleff@vm.uff.br
}

Fernanda Malinosky Coelho da Rosa

Doutoranda em Educação Matemática - Unesp/Rio Claro

malinosky20@hotmail.com

\section{Rosângela Figueira Dornas}

SEERJ; UAB/UFF; FAMATh - Rio de Janeiro/RJ

rfdornas@yahoo.com.br

\begin{abstract}
Resumo
Apresentam-se ações do Laboratório de Ensino de Geometria (LEG), da Universidade Federal Fluminense (UFF), realizadas no âmbito de diversos projetos, nos quais se busca o desenvolvimento de metodologias e estratégias de ensino e aprendizagem, ou seja, de tecnologias educacionais, da capacitação e da qualificação de recursos humanos, no caso, licenciandos e professores de Matemática em formação continuada. Além disso, apresentam-se a fundamentação teórica para tais ações e um exemplo de recurso didático criado e adaptado para o ensino do aluno com deficiência visual. Com isso, busca-se não só oferecer algumas alternativas para incentivar cada licenciando de Matemática ou professor - tanto em sua formação no ensino presencial como no curso de especialização a distância - a desenvolver estratégias que tornem o ensino dos conteúdos mais próximos da realidade da sala de aula, permitindo o desenvolvimento de um pensamento abstrato a partir dos materiais didáticos manipulativos, além de possibilitar a Educação Inclusiva.
\end{abstract}

Palavras-chave: Educação Matemática Inclusiva. Deficiência Visual. Formação de Professores.

\section{Math Education in Virtual Environment and the Inclusive Education: The Geometry Teaching Laboratory's Actions}

\begin{abstract}
We present actions of a Geometry Teaching Laboratory called LEG, in the Universidade Federal Fluminense (UFF), realized under various projects in which seeks to develop methodologies and teaching and learning's strategies, i.e. from educational technologies, training and qualification of human resources, in this case, undergraduate and mathematics teachers in continuing education. In addition, we present the theoretical basis for such actions and a didactic resource's example created and adapted in LEG. Thereby, we seek not only offer some alternatives to encourage each undergraduate student or math teacher - both in their formation in face to face education as in a
\end{abstract}


specialization course by distance - to develop strategies to became the teaching content near the classroom reality, allowing the abstract thinking's development from the manipulative didactic materials, and enable inclusive education.

Keywords: Mathematics Inclusive Education. Visual impairment students. Teachers Education.

\section{Apresentação}

Neste artigo apresentamos ações do Laboratório de Ensino de Geometria (LEG), vinculado ao Instituto de Matemática e Estatística (IME) da Universidade Federal Fluminense (UFF), em Niterói/ $\mathrm{RJ}$, com as quais se busca o desenvolvimento de metodologias e estratégias de ensino e aprendizagem com o uso de tecnologias educacionais, além da qualificação de licenciandos e professores de Matemática em formação continuada. Desde a institucionalização do LEG em 1994, a equipe $^{1}$ visa à criação de recursos educacionais de baixo custo e métodos didáticos adequados ao desenvolvimento de habilidades matemáticas, principalmente geométricas, de alunos da Escola Básica, licenciandos e docentes em formação.

Ao longo de mais de duas décadas, temos constatado que muitos profissionais apresentam dificuldades para a obtenção e aplicação de materiais didáticos manipulativos ou virtuais considerados nos livros e destinados ao Ensino Básico. Muitos professores, principalmente dos anos iniciais, declaram ter duas razões principais para não se sentirem à vontade para aplicar tais materiais em suas salas de aula. A primeira é por não estarem familiarizados com os procedimentos didáticos requeridos pelos materiais manipulativos, e a segunda, é por não terem conhecimento de como reproduzi-los com recursos de baixo custo, principalmente com sucatas.

Por outro lado, no ambiente desse laboratório, também visamos à melhoria do ensino em geral, principalmente de Geometria, e uma melhor preparação do profissional. Nessa perspectiva, desde 2008, a equipe do LEG ampliou a sua atuação e passou também a objetivar a preparação do profissional para a inclusão de alunos com alguma deficiência nas escolas regulares, pois buscamos adequá-lo às necessidades da educação inclusiva que é recomendada pelas leis brasileiras, que colocam a preparação apropriada de todos os docentes como um fator fundamental na promoção do progresso no sentido do estabelecimento de escolas inclusivas. Esse é um assunto recorrente na legislação educacional, pois na formação inicial do professor deve constar a inserção curricular de disciplinas envolvendo o tema, bem como nos cursos de especialização. Dentre as leis mais recentes publicadas, o Plano Nacional de Educação - PNE (2014-2024) - reforça explicitamente essa recomendação ao:

\footnotetext{
${ }^{1}$ Formada por professores da UFF de diferentes departamentos.
} 
incentivar a inclusão nos cursos de Licenciatura e nos demais cursos de formação para profissionais da educação, inclusive em nível de pós-graduação, observado o disposto no caput do art. 207 da Constituição Federal, dos referenciais teóricos, das teorias de aprendizagem e dos processos de ensino-aprendizagem relacionados ao atendimento educacional de alunos com deficiência, transtornos globais do desenvolvimento e altas habilidades ou superdotação; (BRASIL, 2014a, p. 58).

A Lei Brasileira de Inclusão da Pessoa com Deficiência (Estatuto da Pessoa com Deficiência), de julho de 2015, em seu artigo 28, parágrafo XIV, recomenda novamente a "inclusão em conteúdos curriculares, em cursos de nível superior e de educação profissional técnica e tecnológica, de temas relacionados à pessoa com deficiência nos respectivos campos de conhecimento" (BRASIL, 2015, p. 04).

No entanto, comungando com as pesquisadoras Glat e Nogueira, bem sabemos que, embora as leis estejam em vigor, elas nem sempre podem ser aplicadas devido a um déficit na formação do professor, pois

inúmeras são as barreiras que impedem que a política de inclusão se torne realidade na prática cotidiana de nossas escolas. Entre estas, a principal, sem dúvida, é o despreparo dos professores do ensino regular para receber em suas salas de aula, geralmente repletas de alunos com problemas de disciplina e aprendizagem. (GLAT; NOGUEIRA, 2002, p.22).

Frente ao desafio de prepararmos profissionais mais capacitados para lidar com a inclusão, temos no LEG uma ação ativa, pois, há cerca de 8 anos, foi inserido o subprojeto de estudos Vendo com as Mãos em um dos projetos de extensão (com apoio da Pró-reitoria de Extensão da UFF) desenvolvidos no Laboratório: Desenvolvimento de atividades para ampliação do acervo didático do laboratório de ensino de geometria do Instituto de Matemática e Estatística. Esse subprojeto foi realizado inicialmente em parceria com uma escola especializada no trabalho com alunos com deficiência visual, o Instituto Benjamin Constant (IBC), no Rio de Janeiro e, há três anos, no Colégio Pedro II (CPII), uma escola inclusiva com instalações no Rio de Janeiro e Niterói (KALEFF, ROSA, 2012; KALEFF, 2016).

Considerando todas as frentes de ação aqui expostas, as autoras do presente texto lançaram-se em estudos sobre como melhor realizar a adaptação dos recursos didáticos manipulativos concretos e virtuais existentes no LEG, visando não só atender às leis, mas também à demanda, pois haviam observado que alunos com deficiência visual da Escola Básica, visitantes das mostras periódicas do Museu Interativo de Educação Matemática realizadas pelo Laboratório, tinham dificuldades ao manipular e interagir com os materiais expostos à visitação pública, pois estes apresentavam limitações específicas para tais visitantes.

\section{A inclusão e os cursos de formação de professores de matemática na UFF}


Ainda em 2008, por iniciativa da professora Ana Kaleff, o Departamento de Geometria do IME aceitou incluir tópicos que orientam o licenciando sobre a Educação Inclusiva do aluno com deficiência visual, na ementa da disciplina obrigatória Laboratório de Educação Matemática dos Cursos de Licenciatura (diurno e noturno) em Matemática da UFF. A partir de então, no curso noturno, sob a influência das experiências realizadas nos vários projetos de extensão coordenados pela referida professora, não somente nessa disciplina, mas também em outra obrigatória denominada Educação Matemática - Geometria, quando ministradas no âmbito do LEG, é dada ênfase à divulgação de recursos educacionais destinados ao aluno com tal deficiência.

Outra linha de ação é a da formação virtual de professores a distância, via plataforma Moodle, em uma disciplina denominada Tópicos em Ensino de Geometria (TEG). Esta é optativa na grade curricular do curso de Especialização lato sensu em Novas Tecnologias no Ensino da Matemática (NTEM). Esse curso é reconhecido pelo MEC e destinado ao professor de Matemática dos níveis Fundamental e Médio; encontra-se alocado no Laboratório de Novas Tecnologias de Ensino (LANTE), também vinculado ao IME e ao Sistema Universidade Aberta do Brasil (UAB).

A disciplina TEG, desde 2007, tem como coordenadora a professora Ana Kaleff, que também coordena o LEG. Essa disciplina visa levar, de maneira muito objetiva, o professor de Matemática à criação e utilização de um laboratório de ensino de geometria com recursos manipulativos concretos e computacionais. Busca, assim, orientar o profissional a perceber que o ensino dessa área pode ser dinâmico e criativo, inclusive considerando alunos com alguma deficiência visual (cegos ou com baixa visão), bem como leva o docente a revisitar ou a conhecer conteúdos geométricos pouco tratados em cursos de graduação.

No que se segue, antes de detalharmos como temos desenvolvido recursos didáticos para o ensino de conceitos geométricos nos cursos de formação aqui tratados, é necessário que esclareçamos alguns dos desafios que se apresentam aos envolvidos nessa formação, no que concerne à habilidade da visualização, à natureza dos objetos matemáticos e suas representações.

\section{Desafio na formação de professores de matemática}

$\mathrm{Na}$ prática com os licenciandos e professores em formação continuada, optamos sempre por tratar prioritariamente os conceitos matemáticos do ponto de vista do desenvolvimento da principal habilidade com a qual a matemática escolar pode contribuir para a preparação de cidadãos mais aptos à vida em sociedade do século XXI: a habilidade da visualização. Esse caminho foi tomado porque percebemos que, gradativamente, mergulhamos mais fundo em um mundo virtual e computacional. Esse possui uma diversidade de representações cada vez mais reais que, cheias de cores, podem até ser acompanhadas de sons, mas que ainda não nos permitem ter estímulos táteis, 
olfativos e gustativos. Percebemos que cada vez mais dependemos do entendimento de ícones, símbolos, desenhos, fotos, sinais, figuras, gráficos, tabelas, diagramas e seus traçados, nas diversas mídias que, há poucos anos, nem sequer sonhávamos poder existir. Ou seja, o mundo virtual de nossos dias é basicamente um mundo visual, no qual estão desde o livro didático, a TV mais comum e os computadores mais sofisticados.

A habilidade da visualização está intimamente relacionada com o anteriormente colocado e inclui a capacidade de ler, escrever e interpretar corretamente informações gráficas nas suas mais diversas formas de representação: do desenho geométrico, de gráficos cartesianos, de esquemas traçados sobre redes pontilhadas, de esquemas gráficos sem padronização, de tabelas etc. Frente a tudo isso, o ato de interpretar desenhos, figuras, fotos, entre outros, não é importante por si só, mas está intimamente ligado à vida do cidadão comum, pois a interpretação de informações visuais está presente tanto nos simples problemas do dia a dia como em desafios da Engenharia, da Arquitetura, da Medicina, das Artes. Tais representações gráficas podem ser o registro de indicadores numéricos em tabelas e gráficos de esboços de objetos, de imagens impressas em fotos ou em raio-X, de imagens observadas por meio de microscópios, outros meios ópticos ou computadorizados, como ressonância magnética, e até mesmo na forma de imagens pintadas por artistas representando a natureza ou suas visões imaginárias.

A interpretação de informações visuais está em jogo quando tratamos, por exemplo, do mais simples esboço de uma figura geométrica como o triângulo, de um mapa que indique o caminho entre duas localidades, ou, até mesmo, de sofisticadas representações do gráfico de uma planta de um prédio. Por outro lado, a informática e as ferramentas advindas da computação criam, a cada dia, novas situações nas quais as formas virtuais ganham aspectos de uma realidade quase material, abrindo novos rumos para o entendimento das formas visuais que se apresentam no plano da tela do computador. A tecnologia parece nos levar do plano (a duas dimensões) ao espaço (a três dimensões) sem sairmos do lugar, apenas com um clique ou com uma batida em uma tecla do teclado...

Aos professores se apresenta um grande desafio de como, nas aulas de matemática, ajudar os alunos a estarem mais preparados para a compreensão do mundo visual. Além disso, precisam acolher alunos com deficiência visual em nossas salas de aulas. Estamos nos preparando para a educação matemática inclusiva desse aluno? Assim, como podemos preparar o aluno da Escola Básica para enxergar com as mãos e olhos para poder ver com a mente?

A estas perguntas temos buscado repostas no LEG, mas antes de delinearmos algumas delas e exemplificarmos como enfrentamos esse desafio, é necessário que, como professores, nos 
debrucemos a entender como os matemáticos concebem a natureza dos objetos que criam e idealizam, dos quais lançamos mãos em nossas aulas.

\section{Sobre concretude e abstração: a natureza dos objetos matemáticos}

Como professores, devemos estar alerta para o fato de que, embora os objetos matemáticos tenham tido sua origem histórica no mundo físico (com os sistemas de numeração, de quantificação e medição de comprimentos, de áreas, de volumes, de peso, entre outros), atualmente, tais objetos são considerados abstrações matemáticas. Segundo o psicólogo e filósofo francês Raymond Duval, tais objetos necessitam de uma linguagem apropriada para serem expressados e entendidos, portanto, representados, no mundo exterior à mente humana. Porém, para os matemáticos, não há dúvidas de que os elementos geométricos (por exemplo, ponto, reta, plano, espaço, sólidos etc.) pertencem ao mundo das ideias abstratas. No entanto, tais conceitos idealizados necessitam de representações gráficas, isto é, sistemas de linguagens com signos, sinais, desenhos para serem expostos ao mundo exterior ao da mente do matemático, para serem expressados e percebidos por outra pessoa não iniciada nessa ciência (DUVAL, 2003).

$\mathrm{Na}$ escola, no entanto, tal mudança de concepção filosófica sobre a natureza dos objetos matemáticos se mostra como um fator perturbador ao entendimento do significado das definições matemáticas, ou seja, a mudança da concepção deste objeto como representante de um conteúdo do mundo físico, para aquela do objeto como um elemento ideal e abstrato, se apresenta como uma grande dificuldade para os alunos, que não percebem os conceitos, principalmente os geométricos, como abstrações idealizadas pelos matemáticos, embora representadas por meios gráficos.

Frente a tudo isso, a maior parte dos estudantes, e até mesmo professores do Ensino Básico, não aceitam que, ao observarem o desenho de uma figura matemática no livro didático, na lousa, ou até mesmo uma imagem na tela do computador, estão, na realidade, vendo apenas uma representação do objeto matemático, que é a de um conceito abstrato. Portanto, é essa dificuldade do aluno de formar uma imagem na mente e "enxergar com as mãos ou com os olhos", para poder "ver com a mente" tais conceitos abstratos, que nos leva a trazer os recursos didáticos manipulativos concretos e virtuais para a sala de aula. É por meio da observação do recurso concreto (ou virtual) que o aluno pode modelar e representar situações matemáticas, que serão transformadas em representações gráficas, tanto na forma de traçados em desenhos ou de uma linguagem matemática (em uma equação algébrica ou em símbolos numéricos, por exemplo).

A dificuldade de construção de uma imagem mental de um conceito matemático é ainda maior se pensarmos no aluno cego ou com baixa visão, pois, para ele, a manipulação de um recurso 
concreto é imprescindível para que, por meio do tato, perceba a forma, o tamanho, as texturas etc., que vão determinar as características do elemento matemático modelado no recurso manipulativo.

Como apresentamos em Kaleff (2016), na nossa prática temos observado que, frente a um modelo manipulativo concreto de um conceito matemático, o aluno com deficiência visual tateia e manipula (buscando "enxergar" com as mãos) o conceito modelado para obter uma imagem mental advinda da percepção tátil. Por sua vez, o indivíduo com visão normal, frente ao modelo manipulativo (concreto ou virtual) efetivamente enxerga (com os olhos) o conceito modelado e obtém uma imagem mental advinda da percepção visual. Em ambas as situações, é a percepção do conceito/objeto matemático modelado no material manipulativo que permite produzir a imagem mental (na cabeça) do aluno e, portanto, essa imagem não se dá somente por meio restrito da imaginação do indivíduo. São as ações realizadas com as mãos e com os olhos que vão permitir a formação do que a "mente vê".

No que se segue apresentamos a fundamentação teórica para as ações realizadas e para a concepção das atividades e dos recursos didáticos manipulativos (aparelhos, artefatos, jogos etc.), tanto concretos quanto virtuais desenvolvidos no LEG.

\section{A fundamentação teórica: para as ações, recursos didáticos e atividades}

Nas nossas ações no LEG consideramos as recomendações orientadoras da prática escolar e da formação do professor apresentadas nos documentos governamentais do programa Pacto Nacional pela Alfabetização na Idade Certa - PNAIC (BRASIL, 2014b); nos Parâmetros Curriculares Nacionais relacionados ao Ensino Fundamental - PCN: $1^{\circ}$ e $2^{\circ}$ Ciclos; $3^{\circ}$ e $4^{\circ}$ Ciclos (BRASIL, 1998a; 1998b) e ao Ensino Médio - PCNEM (BRASIL, 2000); bem como nas Adaptações Curriculares desses Parâmetros para o aluno com deficiência visual (BRASIL, 1998c).

A fundamentação teórica adotada para as atividades geométricas tem origem construtivista principalmente no Modelo de van Hiele para o desenvolvimento do pensamento em Geometria (VAN HIELE, 1986). Segundo esse Modelo, os conceitos geométricos e suas relações seriam desenvolvidos pelo aluno em cinco níveis de entendimento, por meio de fases bem determinadas de ensino. Partindo do nível cognitivo da visualização do conceito, seguido pelo nível da análise, depois pelo nível da ordenação informal e do nível da ordenação formal, o qual o aluno atingiria o nível do rigor da conceituação do ente geométrico. As atividades para os alunos cegos ou com baixa visão são baseadas principalmente nos artigos publicados na Revista Benjamin Constant ${ }^{2}$. Os estudos apresentados por Harold Jacobs (1974) e João Lucas Barbosa (2004) formam a fundamentação matemática teórica para os temas da Geometria Euclidiana.

\footnotetext{
${ }^{2}$ Disponível em: http://www.ibc.gov.br/?catid=4\&itemid=408. Acesso em: 27 out. 2016.
} 
Gostaríamos de enfatizar que, nas disciplinas citadas anteriormente, insistimos em pontuar o fato de que nada valem os recursos didáticos manipulativos concretos ou virtuais se não forem acompanhados de atividades para o aluno cujas diretrizes educacionais sejam bem determinadas com vistas à aprendizagem significativa dos conceitos matemáticos. Portanto,

não se deve usar o material didático pelo material, o jogo pelo jogo! Resumidamente, pode-se dizer que na sala de aula, não se deve utilizar os materiais didáticos pelos próprios materiais. Ou seja, o professor deve utilizá-los com a preocupação voltada para os obstáculos cognitivos apresentados pelos alunos na construção do conceito, para relacioná-los com as habilidades matemáticas que devem ser desenvolvidas e com a formação do significado matemático (KALEFF, 2008, p.59).

Consideramos que as atividades relacionadas aos recursos manipulativos devam permitir ao professor agir como um verdadeiro mediador do conhecimento, ou seja, fomentando e guiando o estudante para a descoberta e evolução do significado dos conceitos matemáticos, levando esse aluno a interagir com o recurso (aparelho, artefato, jogo etc.) de maneira orientada e a se tornar consciente das propriedades matemáticas modeladas no material. Por outro lado, tais atividades devem levar o aluno a interagir com o recurso didático com vistas à descoberta das propriedades modeladas do conceito em estudo e também a uma representação gráfica (com traçados de desenhos e gráficos) ou linguística (com símbolos e sinais). Dessa maneira, partindo de um recurso didático modelador (concreto ou virtual) do conceito, buscamos levar o aluno às suas representações matemáticas.

Cabe lembrar que nossas estratégias de elaboração das atividades e mediação do aluno na sua interação com o recurso didático comungam com as apresentadas pelas educadoras matemáticas Bartolini Bussi e Alessandra Mariotti, pois consideramos o recurso didático como uma ferramenta de mediação semiótica quando usada pelo professor para intervir intencionalmente na aprendizagem da representação de um conteúdo, por meio de símbolos e sinais (BUSSI; MARIOTTI, 2008).

\section{O Caderno de Atividades e um exemplo de recurso didático}

Cada recurso didático desenvolvido no LEG é acompanhado por um Caderno de Atividades no qual constam todas as orientações para o aluno realizar as atividades com o recurso, sendo que todas as figuras e desenhos são em alto-relevo. O texto das orientações é escrito tanto em fonte impressa em tipo grande (no mínimo com 18 pontos), destinado ao aluno com visão normal ou baixa, como em uma versão em Braille, para os cegos. Cabem aqui algumas considerações sobre os resultados das diversas aplicações realizadas para alunos com deficiência visual do Ensino Fundamental e do Ensino Médio. Pudemos observar, por exemplo, que em nenhum desses níveis de ensino 
deveríamos iniciar o tema "áreas", partindo de jogos do tipo quebra-cabeça plano, cujas peças modelassem polígonos com alguma irregularidade. Várias dessas aplicações já apresentamos em outro artigo em descrição pormenorizada (KALEFF, ROSA, 2012). A partir de 2012, criamos diversas versões de jogos bem simples (com 2 a 5 peças) com figuras geométricas elementares (quadrados e triângulos), que passaram a servir de introdução à apresentação do jogo tangram estrelado, que descrevemos a seguir, e também para atividades introdutórias ao tema "polígonos equivalentes" (KALEFF, 2016).

O material completo do tangram estrelado é composto por um quebra-cabeça com formato de uma estrela de quatro pontas que contém 7 peças, cinco pranchas vazadas em baixo relevo, com diferentes formatos, uma prancha com malha quadriculada em alto-relevo de material antiderrapante e o Caderno de Atividades, que podem ser vistos na Figura 1. As pranchas vazadas e as peças do quebra-cabeça foram confeccionadas com papelão do tipo Paraná, cujo acabamento foi feito com fita adesiva colorida. Em cada peça foi colocada uma alça pequena de fio de linha encerada, que tem por objetivo facilitar o manuseio da peça por parte do aluno com deficiência visual.

Figura 1 - Material completo do tangram estrelado e peças do jogo.
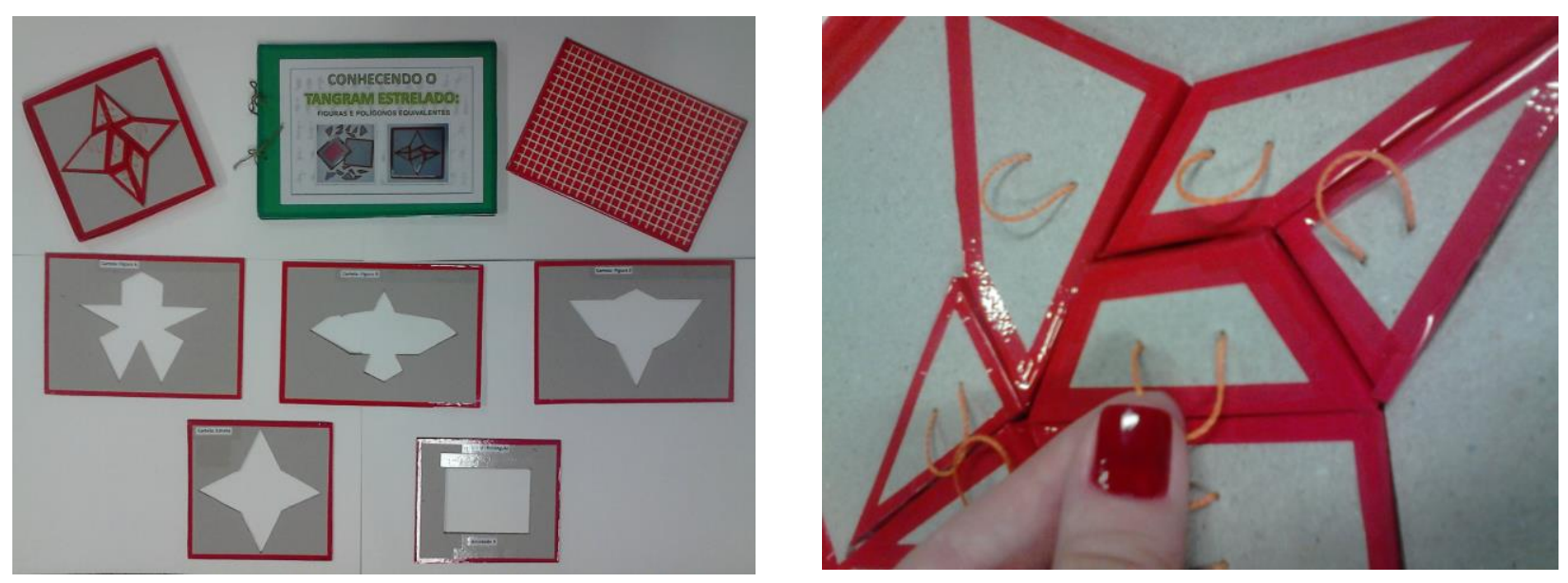

Fonte: Elaborada pelas autoras a partir do acervo do LEG

O Caderno de Atividades que orienta este material inicia com uma breve apresentação do jogo e é pedido que o aluno observe as peças, a fim de reconhecer as suas formas e verificar se, dentre elas, existem formatos iguais ou peças com mesmo número de lados. Em seguida, pedimos que construa uma figura de sua imaginação, utilizando todas as peças do jogo. Nas ações seguintes, propomos que o aluno faça construções sucessivas de algumas das figuras apresentadas nas pranchas vazadas. Como todas as peças do jogo são utilizadas em cada uma das construções, instigamos o aluno a perceber a relação de igualdade entre as áreas das figuras construídas, introduzindo, desse modo, o conceito de figuras equivalentes. Após, são realizadas atividades similares, porém utilizando formas de poligonais já conhecidas (de triângulo, retângulo, 
paralelogramo e trapézio). A seguir, com o auxílio da malha quadriculada, pedimos ao aluno que faça a contagem das quadrículas, chegando às áreas ocupadas pelas figuras construídas. A partir disso, tentamos fazer com que o aluno escreva as fórmulas das áreas de alguns dos polígonos representados com as peças. Finalmente, é proposto um desafio: o aluno deve construir a caixa ideal para guardar o jogo. É dessa maneira que o aluno é conduzido a fazer a transição do conceito de polígono não-convexo (com a forma da estrela) para o de convexo, uma vez que a caixa ideal deverá ter a forma de um prisma de base retangular, cujo cálculo da área é muito fácil. Ou seja, o aluno estará trabalhando o conceito de polígonos equivalentes.

\section{A guisa de conclusão}

Criar alternativas para que o aprendizado da geometria se torne mais significativo é o objetivo do LEG, tanto no ensino presencial quanto na Educação a Distância (neste, através da disciplina TEG). Assim, temos procurado não só oferecer alternativas, mas também incentivar cada licenciando de Matemática ou professor a desenvolver estratégias que tornem o ensino dos conteúdos mais próximos da realidade da sala de aula e permitam desenvolver o pensamento abstrato do aluno a partir dos materiais didáticos manipulativos, além de possibilitar a inclusão na escola regular, especialmente daquele com dificuldades visuais.

Esperamos que este relato possa também incentivar outros formadores a dar mais ênfase à criação de ferramentas didáticas que possam vir a fomentar a educação matemática inclusiva, pois nada é mais gratificante do que recebermos mensagens de ex-alunos-professores da disciplina TEG, que expressam a satisfação por perceber como estão mais preparados para enfrentar os desafios da profissão e a fomentarem o avanço de seus próprios alunos da escola básica, em relação ao aprendizado de geometria. Através dessa disciplina, não só recebemos esse retorno, mas somos constantemente desafiados a pensar em como um ambiente virtual pode e deve ser utilizado para desenvolver atividades, propiciando experiências marcantes para o usuário.

Toda nossa experiência no LEG demonstra que a Educação precisa estar cada vez mais contextualizada, interligada aos novos tempos e às tecnologias, participando assim da cultura científica e tecnológica que nos é apresentada e que pode contribuir para o avanço do conhecimento, para a inclusão e para uma realidade mais propícia ao aprendizado da Matemática.

\section{Referências}

BARbOSA, J. L. M. Geometria Euclidiana Plana. 5 ed. Rio de Janeiro: Sociedade Brasileira de Matemática. 2004. 203p. 
BRASIL. Ministério da Educação. Secretaria de Educação Fundamental. Parâmetros curriculares nacionais. Adaptações curriculares. Secretária de Educação Especial. Brasília: MEC/SEF. 1998a.

BRASIL. Ministério da Educação. Secretaria de Educação Fundamental. Parâmetros curriculares nacionais: terceiro e quarto ciclos do ensino fundamental: Matemática ( $5^{\underline{a}}$ a $8^{\underline{a}}$ séries). Brasília: MEC/SEF. 1998b.

BRASIL. Secretaria de Educação Fundamental. Secretaria de Educação Especial. Parâmetros curriculares nacionais: Adaptações Curriculares. Brasília: MEC/SEF/SEESP, 1998c.

BRASIL. Ministério da Educação. Secretaria de Educação Média e Tecnologia. Parâmetros curriculares nacionais - ensino médio. Brasília: MEC/SEF, 2000.

BRASIL. Plano Nacional de Educação 2014-2024: Lei no 13.005, de 25 de junho de 2014, que aprova o Plano Nacional de Educação (PNE) e dá outras providências. Brasília: Câmara dos Deputados, Edições Câmara, 2014a.

BRASIL. Ministério da Educação, Secretaria de Educação Básica, Diretoria de Apoio à Gestão Educacional. Pacto nacional pela alfabetização na idade certa: Geometria. Brasília: MEC/ SEB. 2014b. 96 p.

BRASIL. Casa Civil. Lei no 13.146, de 6 de julho de 2015. Institui a Lei Brasileira de Inclusão da Pessoa com Deficiência (Estatuto da Pessoa com Deficiência). Brasília, 2015.

BUSSI, M. G. B.; MARIOTTI, M. A. Semiotic mediation in the mathematics classroom: artifacts and signs after a Vygotskian perspective. In: ENGLISH. L ET AL (Eds.) Handbook of international research in Mathematics Education. 2. Ed. Mahwah: Lawrence Erlbaum, 2008, p. 746-783.

DUVAL, R. Registros de representações semióticas e funcionamento cognitivo da compreensão em Matemática. In: ALCÂNTARA MACHADO, S. D. (Ed.) Aprendizagem Matemática. São Paulo: Papirus, 2003, p.11-34.

GLAT, R.; NOGUEIRA, M. L. L. Políticas educacionais e a formação de professores para a Educação Inclusiva no Brasil. Integração, Brasília, DF: v. 24, ano 14, p. 22-27, 2002.

JACOBS, H.R. Geometry. Nova York: Freeman and Co., 1974, 701p.

KALEFF, A. M. M. R. Tópicos em ensino de Geometria: A Sala de Aula Frente ao Laboratório de Ensino e à Historia da Geometria. Rio de Janeiro: UFF/UAB/CEDERJ, 2008. 223 p.

KALEFF, A. M. M. R. (Org.) Vendo com as mãos, olhos e mente: Recursos didáticos para laboratório e museu de Educação Matemática Inclusiva do aluno com deficiência visual. Niteroi-RJ: CEAD / UFF, 2016. CD-ROM.

KALEFF, A. M. M. R.; ROSA, F. M. C. Buscando a Educação Inclusiva em Geometria. Revista Benjamin Constant, v. 31, abril, Rio de Janeiro: Instituto Benjamin Constant, p. 22-33. 2012. Disponível em http://www.ibc.gov.br/?catid=160\&blogid=1\&itemid=10223. Acesso em $21 \mathrm{de} \mathrm{jul.}$ 2016.

VAN HIELE, P. M. Structure and Insight: A theory of Mathematics Education. New York: Academic Press.1986. 246p. 